Int. J. Electrochem. Sci., 12 (2017) 4086 - 4095

\title{
Electrochemical DNA Sensor for hly Gene of Listeria Monocytogenes by Three-Dimensional Graphene and Gold Nanocomposite Modified Electrode
}

\author{
Lijun Yan, Wenshu Zhao, Zuorui Wen, Xiaoyan Li, Xueliang Niu, Yaqi Huang, Wei Sun*
}

Key Laboratory of Tropical Medicinal Plant Chemistry of Ministry of Education, College of Chemistry and Chemical Engineering, Hainan Normal University, Haikou 571158, P. R. China

*E-mail: swyy26@ hotmail.com

doi: $10.20964 / 2017.05 .04$

Received: 25 January 2017 / Accepted: 6 March 2017 / Published: 12 April 2017

\begin{abstract}
A high performance electrochemical DNA sensor with three-dimensional graphene (3DGR) and gold $\mathrm{Au}$ ) nanocomposite modified electrode was developed for sensitive analysis of specific hly gene of Listeria monocytogenes. Nanocomposite was synthesized by electrochemical deposition of 3DGR and $\mathrm{Au}$ in turn on carbon ionic liquid electrode (CILE). Mercaptoacetic acid (MAA) was self-assembled on $\mathrm{Au} / 3 \mathrm{DGR} / \mathrm{CILE}$ by the specific binding of Au-S bond, which was used for the covalently linkage of ssDNA probe sequences. The fabricated ssDNA/MAA/Au/3DGR/CILE could interact with the target ssDNA sequence and the hybridization was recorded by using electrochemical indicator methylene blue (MB). Based on the reduction current of MB, this electrochemical DNA sensor was able to detect the target ssDNA sequence of hly gene with a wide linear concentration range $\left(1.0 \times 10^{-14}\right.$ to $1.0 \times 10^{-6}$ mol L ${ }^{-1)}$ and a low detection limit $\left(3.3 \times 10^{-15} \mathrm{~mol} \mathrm{~L}^{-1}, 3 \sigma\right)$. Furthermore, this biosensor was used to the detection of PCR amplification sample of Listeria monocytogenes.
\end{abstract}

Keywords: three-dimensional graphene, dendritic gold, electrochemical deposition, methylene blue, electrochemical DNA sensor.

\section{$\underline{\text { FULL TEXT }}$}

(C) 2017 The Authors. Published by ESG (www.electrochemsci.org). This article is an open access article distributed under the terms and conditions of the Creative Commons Attribution license (http://creativecommons.org/licenses/by/4.0/). 